\title{
Dr. S. J. Stephen Gold Medal 2020
}

The Dr S J Stephen Gold medal and research award is awarded by the College of Surgeons of Sri Lanka, for the best research paper published over the preceding year in the Sri Lanka Journal of Surgery.

Dr. Samuel Jeyarajah Stephen had his primary and secondary education at Central College, Jaffna and obtained his final MBBS from the University of Colombo in 1955. He pursued General Surgery and later trained in Cardiovascular surgery in UK, Germany, India and USA and obtained FRCS and MS.

In 1964, he was appointed the Consultant Thoracic Surgeon, GH Jaffna and later on, in GH Rathnapura. It was here in 1969, with the assistance of Dr. Neil Hamel, he assembled a heart lung machine. He then went on to close ASD's on pump which was the first proper open-heart surgery performed out of Colombo.

He served as the Chief Consultant Cardiothoracic surgeon, General Hospital, Colombo from 1976 to 1994. Following retirement, he served as in the Sri Jayewardenepura General Hospital.

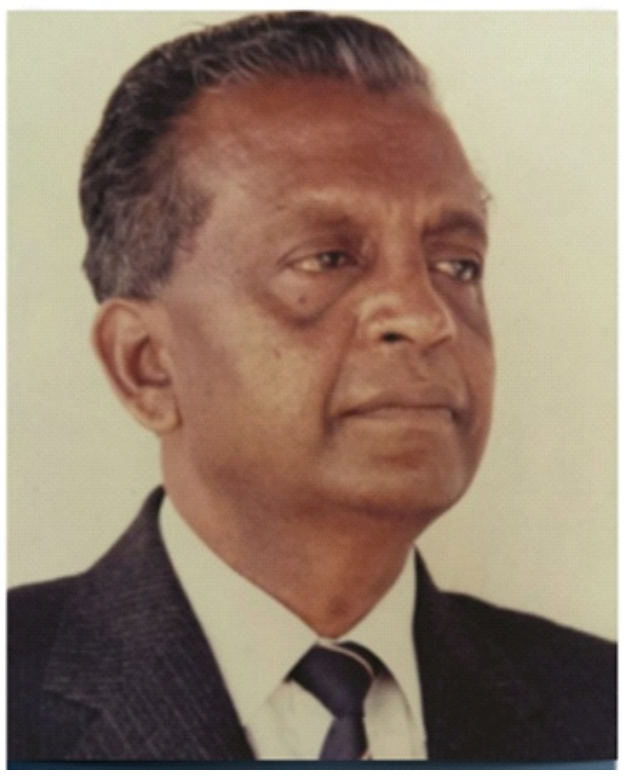

He was a trainer and examiner in surgery for the Postgraduate Institute of Medicine and the Chairman, Board of Study in Surgery for many years. He was the President of the College of Surgeons of Sri Lanka from 1988 to 1989. He was the President of SLMA, Sri Lanka Heart Association and Association of Cardiology - SAARC countries along his career. He was awarded the prestigious title of Hunterian Professor by the Royal College of Surgeons of England in 1988 for the lecture on "Changing patterns of mitral stenosis in childhood and pregnancy". He had published numerous papers in local and international journals on many aspects of cardiac and thoracic surgery. He was honoured with the National Honour "Deshabandu" for meritorious service to the nation by the President of Sri Lanka in 1987.

\section{S. J. STEPHEN GOLD MEDAL 2020 was awarded to Dr. Sittampalam Rajendra.}

Rajendra S. Chronic autoimmune thyroiditis: a challenging clinical entity in surgical practice. Sri Lanka Journal of Surgery. 2019;37(4):03-10.

http://doi.org/10.4038/sljs.v37i4.8656 